\title{
La nostalgia restauradora, el ocaso de la hermenéutica del punto de vista ajeno
}

\author{
The restorative nostalgia, the descent of hermeneutics \\ of the other's point of view
}

JORGE MONTESÓ VENTURA*

\begin{abstract}
Resumen: La nostalgia es el efecto emocional que provoca la mirada que busca entre los recuerdos el hogar desaparecido, añorado. En sí misma, en tanto pesquisa en la memoria, implica cierto grado de ensimismamiento e individuación, pues los recuerdos son en extremo particulares, un retorno al yo. Cuando esta nostalgia se reviste de un afán restaurativo, cuando alberga pretensiones sociales y políticas, dicho retorno se traduce en un marcado distanciamiento entre el propio punto de vista y el de cualquier otro, hasta resultar una amenaza para la necesaria hermenéutica del punto de vista ajeno que demanda toda convivencia.

Palabras clave: Nostalgia, perspectiva, proyecto de vida, hermenéutica, alteridad, pasado.
\end{abstract}

\begin{abstract}
Nostalgia is the emotional effect that causes searching between memories the disappeared home, longed for. In itself, while researching in memories, it implies a certain degree of self-absorption and individuation, because the memories are in extremely particular, a return to the self. When this nostalgia is filled with a restorative eagerness, when it has social and political pretensions, this return translates into a marked distancing between one's point of view and that of any other, until it becomes a threat to the necessary hermeneutics of the other's point of view that demands all coexistence.
\end{abstract}

Keywords: Nostalgia, perspective, life project, hermeneutic, otherness, past.

\section{Introducción}

Cada especie tiene su escenario natural, dentro del cual cada individuo, o grupo de individuos, se recorta un escenario más reducido. Así el paisaje humano es resultado de una selección entre las infinitas realidades del universo, y comprende solo una pequeña parte de estas. Pero ningún hombre ha vivido íntegro el paisaje de la especie. Cada pueblo, cada época, operan nuevas selecciones sobre el repertorio general de objetos "humanos", y dentro de cada época y cada pueblo, el individuo ejecuta una

Recibido: 28/12/2017. Aceptado: 21/10/2018.

* Responsable del departamento de Antropología filosófica del Centre d'Estudis Antropològics ACAF. E-mail: jmonteso.acaf@gmail.com / Líneas de investigación: Antropología filosófica, teoría del conocimiento y fenomenología. Dos publicaciones recientes: Montesó, J. (2016). La atención en el pensamiento de Ortega y Gasset. València: Centre ACAF; Montesó, J. (2017). "La atención como fenómeno de apertura cognoscitiva al mundo. Una aproximación fenomenológica”. Contrastes. Revista internacional de filosofía, 22 (2), 107-122. 
última disminución. Sería preciso yuxtaponer lo que cada uno de nosotros ve en el mundo a lo que ven, han visto y verán los demás individuos para obtener el escenario total de nuestra especie (OC, III, 752-753).

En 19241, Ortega llevaba cerca de ocho años -desde la aparición de "Verdad y perspectiva"2- desplegando y desarrollando su perspectivismo. Durante todo ese periodo, sin excepción, apeló con la misma fuerza tanto a la individualidad radical del punto de vista -defendiendo que "el punto de vista individual me parece el único punto de vista desde el cual puede mirarse el mundo en su verdad. Otra cosa es un artificio" (OC, II, 162)- como la posibilidad de su complementación a través del punto de vista ajeno, de la mirada del prójimo, con la intención de "componer el torrente de lo real" (OC, II, 163). En otras palabras, pese la defendida "fatal" radicalidad del punto de vista individual, a su parcialidad irrepetible e intransferible que hace de nosotros sujetos únicos, solitarios e insustituibles, no cejó Ortega en su empeño de promover que esa "fatalidad", a su vez, era la misma cualidad que nos tornaba necesarios:

la peculiaridad de cada ser [...] es precisamente el órgano por el cual puede ver la porción de realidad que le corresponde [...] la verdad integral solo se obtiene articulando lo que el prójimo ve con lo que yo veo, y así sucesivamente (OC, III, 616).

Pese a la condena que el madrileño recordaba recurrentemente en términos de soledad radical, el hecho de que nuestra perspectiva sea irrepetible no significa por ello que no pueda ser almacenable o comunicable. Vemos en Ortega cierto aire de posibilidad en el atisbo de una verdad, en su acepción trascendental, que asoma por encima de su condición histórica; considera Ortega que entre todos los hombres podemos llegar a vivir lo Humano ${ }^{3}$, pues la verdad es y contiene múltiples perspectivas, igualmente verídicas y auténticas todas ellas. Así, aunque la verdad se demuestre siempre resignadamente irrealizable en su compleción, pues lejos queda el intento de aspirar a la omnímoda situación divina, nos queda la alternativa de reconstruir Babel, de contar con el otro, con la complementariedad necesaria de su mirada, de su selección en el amplio horizonte histórico para, dentro de nuestros límites, aproximarnos a la idea de verdad. Un objetivo que, en tanto seres mundanos, solo podemos conseguir yuxtaponiendo el mayor número posible de perspectivas a la nuestra propia. Por ello, inspirado por las doctrinas goethianas, animaba Ortega a que, en vez de disputar, integrásemos nuestras visiones (Cfr. OC, II, 163), defendiendo que todo hombre es poseedor de su exigua porción de realidad la cual, unida a las demás, nos cede un complejo de significación integrador.

1 Las Atlántidas se publica en la Revista de Occidente en octubre de 1924, se incluye en las Obras completas en su tercer tomo (OC, III, 743).

2 En 1916 aparece, en el primer volumen de El espectador, este breve pero denso artículo donde Ortega expone, de una manera ya consolidada, sus principios perspectivistas los cuales, a partir de este momento, estallan hallando su radicación en múltiples terrenos de estudio antropológico llegando su onda expansiva hasta el fin de sus días.

3 “'Solo entre todos los hombres llega a ser vivido lo humano" -dice Goethe" (OC, II, 163). 
Dicho esto y sin embargo, transcurridos casi cien años de aquellos anhelos humanistas, poco parece quedar de aquel espíritu integrador. El halo de esperanza en la promesa del otro, en la sospecha de que la verdad de las cosas se halla más cerca si conseguimos armonizar el punto de vista ajeno con el nuestro propio en una hermenéutica de las vidas ajenas ${ }^{4}$, o no ha calado debidamente entre la sociedad occidental, o las cosas ya no se ven con los mismos ojos. No podemos ignorar que nos separan, entre muchos hitos, un holocausto y dos bombas atómicas; que la promesa comunista se desvaneció como el humo de una hoguera llevándose consigo la esperanza utópica; que, tras un tiempo de aparente reencuentro enmascarado por la ilusión del bienestar, la sociedad se vuelve a sentir perdida, desorientada, desesperanzada frente a un futuro incierto que no asegura el desarrollo de un proyecto de vida que dote de sentido su caminar mundano. No es casualidad que Bauman $(2017,62)$, sociólogo reputado, afirme que los millenials "son la primera generación de postguerra que expresa un temor a retroceder (en vez de avanzar) en estatus social con respecto al alcanzado por sus padres". Por vez primera en mucho tiempo, una generación presagia un futuro que, sin remedio aparente, desmejorará sus condiciones de vida. Las causas son plurales, enumerarlas sería una tarea inacabable, muchos apelan a un exceso de globalización; a la injerencia de un capitalismo atroz que sobrepasa y somete a los estados quienes, sin atisbo de hegemonía, pervierten el contrato social con sus ciudadanos; también al incremento de la desigualdad, tan terrible como la falta de oportunidades y de arraigo; qué decir de los movimientos migratorios, de la sabida pero a la vez ignorada devastación del planeta... el número de factores de desprotección que sufre la población civil superan demasiado la capacidad del individuo de resarcirse y luchar por ejecutar su propio proyecto de vida, hallándose este, como poco, indefenso frente a la incertidumbre. No en vano la resiliencia se ha convertido en un tótem terapéutico, casi en un objetivo en sí mismo. Tal desabrigo no resulta inocuo, trae consigo un conjunto de consecuencias que afectan no solo al comportamiento humano o social, la hondura de la infección es tal que llega a marcar incluso la disposición misma del sujeto en tanto ser-en-el-mundo, al modo en que este se da y se dispone al horizonte -tan hostil e insolidario- afectando el modo de ver la realidad, de establecer nuestra perspectiva del mundo, pues su hostilidad altera de parte a parte la sensibilidad e intereses del sujeto respecto de los que veíamos en tiempos pasados.

Nuestra perspectiva de la realidad en torno, como analizaremos a continuación, es fruto de los movimientos de nuestra atención que, a su vez, se mueve por los intereses y preferencias del sujeto... hoy en día, nuestra atención se vierte sobre aspectos de la realidad muy distintos a los que atendía, por ejemplo, Ortega. Hoy en día, frente a un presente doliente y un futuro incierto, el sujeto se ve cada vez más forzado a desconectar de su realidad en torno para buscar subterfugio en el único tiempo que, por exclusión, le resta a la mano, su propio pasado. Como anota Lowenthal $(1997,9)$, “a medida que las esperanzas de progreso se desvanecen, la herencia histórica nos trae el consuelo de la tradición" 5 ; siendo que el destino deseado se aleja de nuestro alcance, construimos nuestros planes de vida -configurando así nuestra disposición para con el mundo- sobre lo que nos queda a la mano: un pasado recordado, maleable, nostálgico, particular; un pasado que nadie puede

4 Las Atlántidas. OC, III, 754.

5 Traducción propia del original en inglés. 
arrebatarnos ni prohibirnos, pues "las irreductibles oscuridades del pasado, la multiplicidad de interpretaciones de las que toda selección de hechos pretéritos es susceptible, y el resultante carácter incompleto y polémico [...] son precisamente las ventajas que presenta" (Bauman 2017, 68); un pasado que, pese alimentarse de la memoria colectiva, se halla solo en uno mismo, en sus recuerdos, en sus anhelos, en la interpretación personal que de ellos haga. La consecuencia es directa: un irremediable retorno al yo que, por su condición, lleva consigo una creciente desconfianza frente a quien no lo es, en tal caso el otro y su forma de ver el mundo.

En el presente artículo, pues, trataremos de mostrar cómo esa merma en el proyecto vital del sujeto convierte a la nostalgia en la sensibilidad primera del sujeto occidental contemporáneo, en un fondo determinante en la tendencia de nuestra atención a la hora de establecer el conocimiento del mundo, esto es, nuestra perspectiva o punto de vista de la realidad, la cual, por esa condición nostálgico-restaurativa, acaba construyéndose lejos del punto de vista ajeno.

\section{Perspectiva y proyecto de vida}

En Perspectiva y verdad, Rodríguez Huéscar rescataba la idea de que en toda percepción existe un principio rector o ley del interés ${ }^{6}$ que le subyace. Sugería que toda percepción, entendiendo percepción en su valor etimológico (per-captare) ${ }^{7}$, es, como toda vivencia, intencional y, en tanto mantiene una intención, interesada. Citaba al propio Ortega cuando decía que "si no hubiera más que un ver pasivo quedaría el mundo reducido a un caos de puntos luminosos. Pero hay sobre el ver pasivo un ver activo que interpreta viendo y ve interpretando; un ver que es mirar" (OC, I, 769), que es auténtica percepción.

Nuestra percepción como acto vive de la percepción como presencia del mundo ${ }^{8}$, es nuestro anclaje en él ${ }^{9} \mathrm{y}$, en consecuencia, implica mucho más que la puesta en marcha de los órganos sensitivos. Sobre la acción mecánica (fisiológica) de nuestros sentidos interviene la atención que, en su emergencia, se ve administrada por un sinfín de condicionantes, la mayoría vinculados a nuestra historia de vida (biográficos): hablamos de conceptos o ideas, de la memoria o experiencias previas, de emociones, necesidades, expectativas, preferencias... una profusión de elementos que dotan a la primaria captación sensitiva de un determinado sentido, de una organización en la percepción que, más allá de sensaciones, nos permite captar "cosas". Ello sucede porque nuestra salida al mundo no es la de un yo desinteresado que se limita a recibir estímulos de manera pasiva, sino la de un yo histórico que se halla

6 Rodríguez Huéscar, A. (1985), Perspectiva y verdad, Madrid: Alianza, p. 101. Para el autor, la mirada va regida por una ley de la atención, la cual lo está a su vez por una ley del interés. Así, toda percepción de la realidad estará determinada por el sistema de intereses que albergue el sujeto en cada caso.

7 Percaptare alude no solo a la visión de las cosas, sino también a la captación del sentido de las mismas, al modo de ver, a la percepción de la naturaleza interna de la cosa. De ahí que "si devolvemos a la palabra percepción su valor etimológico -donde se alude a coger, apresar- el concepto será el verdadero instrumento u órgano de la percepción y apresamiento de las cosas" (OC, I, 784).

8 Cfr. HUSSERL, E. (2013), Ideas relativas a una fenomenología pura y una filosofía fenomenológica, México: FCE, UNAM, IIF.

9 Cfr. San Martín, J. (2008), "La percepción como interpretación”. Investigaciones fenomenológicas, 6, pp. 19 y 29. 
colmado de necesidades, de intereses, motivado por la consumación de un proyecto de vida que le empuja a interaccionar activamente con el mundo en torno. Ese sistema de intereses, el cual responde al proyecto vital de cada cual, es quien rige nuestras miradas, es el corazón que reparte los acentos ${ }^{10}$ y actúa como la mano que enarbola la linterna del entendimiento, moviendo el foco luminoso ${ }^{11}$ de la percepción -la atención- hacia aquellos aspectos de la realidad que le son interesantes, atendiendo esto, desatendiendo lo demás, conformando nuestro punto de vista o perspectiva de la realidad.

Por ello afirmamos que para conocer el mundo en torno debemos, como poco, atenderlo ${ }^{12}$. Sin atención, sin el despliegue de la percepción interesada, no hay acceso ejecutivo del yo a la circunstancia, no se producen los necesarios procesos selectivos, de ordenación de planos, jerarquización de impresiones, filtrajes y fijaciones que necesito para tomar consciencia de los objetos con los que estoy naufragando. Y aquí aparece un matiz importante, pues el hecho de reparar en tales objetos, de tomar consciencia de ellos, significa que ya estaban ahí antes de ser atendidos por mí, que ya contaba con ellos en mi vivir, aunque no ha sido hasta que se han vuelto objeto de mi cuestionamiento que los he atendido debidamente. Ser cuestión-de significa que buscamos el ser de algo y esto, a su vez, implica que ya tenemos cierta relación con ese algo -pues lo buscamos-. "El entendimiento es una linterna que necesita ir dirigida por una mano y la mano necesita ir movilizada por un afán preexistente [...], solo se encuentra lo que se busca" (OC, VIII, 325-326). Reparar-en, tomar consciencia-de, sucede cuando, guiados por una determinada idea o concepto preexistente, o por un interés determinado, salimos al mundo con la intención de hallar aquellos elementos sensibles que respondan, como correlatos objetivos, a nuestra idea previa ${ }^{13}$. ¿Qué es la atención sino un "buscar el objeto de antemano [...] una preferencia anticipada, preexistente en nosotros, por ciertos objetos" (OC, VI, 210)? Nunca percibiremos, pues, aquello de lo que, de un modo u otro, no sepamos o tengamos interés por encontrar. Salimos al mundo tras una mirada motivada por el conjunto de preferencias anticipatorias que, en cada momento, espolean nuestra voluntad; tras esa ley del interés ${ }^{14}$.

10 Para Ortega, el corazón es esa sensibilidad que aglutina el sistema de intereses y preferencias, un corazón que reparte los acentos (OC, II, 163); una máquina incansable de preferir y desdeñar (OC, VIII, 369); es el alma o el fondo insobornable donde descansan las necesidades que, junto al espíritu, establecen los intereses que mueven todos nuestros actos intencionales, nuestras vivencias y, entre ellas, la percepción de la realidad.

11 La idea del foco luminoso la adquiere Ortega del símil scheleriano entre atención y el cono luminoso de un faro (cfr. Morón Arroyo, C. (1968), El sistema de Ortega y Gasset, Madrid: Alcalá, p. 204). Este símil se da recurrentemente a lo largo de la historia a causa de la sensación de claridad perceptiva que provoca la atención en su fijación. Lo podemos hallar en autores que van desde los pitagóricos hasta Empédocles o Platón llegando a Lucrecio, Tomás de Aquino o Buridán y, a través de Descartes y Leibniz, a Wolff, Müller, Lotze, Herbart, Wundt, James... Ver Roselló, J., Munar, E., Obrador, P., Cardell, E., (2007), "Historia conceptual de la atención”. Revista de historia de la Psicología, vol. 28, núm. 2/3, pp. 59-65.

12 "Se olvida demasiado la humilde perogrullada de que para ver hay que mirar, y para mirar hay que fijarse, es decir hay que atender" (OC, III 895).

13 Cfr. Schapp, W. (1919), Beiträge zur Phänomenologie der Wahrnehmung, Gotinga: M. Niemeyer, Halle/S.

14 La cual rememora el ordo amoris scheleriano por el que ciertas emociones pueden motivar nuestra atención hacia determinadas cosas (ver Scheler, M. F. (2001), Ética: nuevo ensayo de fundamentación de un personalismo ético, Madrid: Caparrós). 
Así, muy resumidamente, es cómo obtengo mi personal e intransferible perspectiva de la realidad, la que permite que esta sea verdadera para mí y alcance a conformar mi propio "paisaje" o, lo que es lo mismo, mi mundo. Decía Morón Arroyo $(1968,204)$ que "entre las posibilidades que el ambiente nos brinda, [...] tenemos capacidad para percibir solo aquellas que se relacionan con nuestro proyecto vital". De aquí que afirmemos que nuestra salida al mundo sea, obviamente, en perspectiva pero, a la vez y precisamente por ello, necesariamente en pre-spectiva, pues implica un pre-ver que "en su última realidad, [...] y aún antes que una pre-spectiva, es una pro-spectiva" (Rodríguez Huéscar 1985, 116), dado que, aunque sea una mirada anticipada, es una mirada que tiende (ad-tiende) al futuro, que busca, que pretende hallar aquello que necesita, que le interesa. Nuestra mirada al mundo y, con ella, toda nuestra comprensión del mismo, responde de manera directa al proyecto de vida que, como marco de referencia ${ }^{15}$, materializa nuestro modo de existir, cristalizando ese afán que, preexistente en nosotros, nos arroja al mundo de manera intencional. Tal es la importancia de nuestro proyecto de vida a la hora de conformar nuestra perspectiva del mundo.

\section{La hermenéutica del punto de vista}

Así, nuestra perspectiva de la realidad está, pues, circunscrita a lo que somos, a nosotros en tanto proyecto, en tanto conjunto de intereses, también a las necesidades que estimulan tales intereses, a nosotros en tanto cuerpo. Las limitaciones que esto supone a la hora de captar la verdad en su compleción, para el caso la totalidad de las cosas o las cosas en su plenitud, son ingentes. Aunque nuestros sentidos no nos den como tal la percepción -pues, como hemos visto, interviene también la determinación atencional-, es cierto que en tanto seres corpóreos no podemos ir más allá de ellos -al menos por lo que respecta a la percepción de la realidad en torno-, hasta nuestra capacidad de procesamiento de información es limitada; nuestra percepción de la realidad se circunscribe necesariamente a un determinado rango de impresiones ${ }^{16}$ de las que, además, hemos de elegir cuáles atender y cuáles no según nuestros intereses. Tal es así que el propio Ortega llegó a afirmar que, pese a su sencillez aparente, "yo no he acabado de ver nunca una hoja" (OC, IX, 601). En la percepción de la realidad mundana no podemos trascender nuestra situación en cada caso; constreñidos a nuestro cuerpo, no alcanzamos la ubicuidad por lo que "tenemos que contentarnos con tener de ella solo 'aspectos"” (OC, IX, 603); dadas nuestras limitaciones existenciales, el objeto, aunque sí en sí mismo ${ }^{17}$, nunca se nos da como totalidad en la percepción:

15 Marcos de referencia o frames, estructuras mentales que conforman nuestro modo de ver el mundo. Conforman las metas que nos proponemos, los planes que hacemos, nuestra manera de actuar y aquello que cuenta como el resultado bueno o malo de nuestras acciones (cfr. Lakoff G. (2007), No pienses en un elefante: lenguaje y debate político, Madrid: Complutense 2007,p. 4)

16 La realidad alcanza rangos o valores que exceden la capacidad perceptiva de nuestros sentidos (ultrasonidos o infrasonidos; radiaciones ultravioleta e infrarroja, etc.).

17 Nuestros sentidos perciben la cosa "en un proceso continuo de percepción [...]. Pero cada una de las percepciones de este proceso es ya una percepción de esta cosa" (Husserl 2014, 707), esto es, a pesar de la insatisfacción que, como seres mundanos, debemos arrastrar por no alcanzar la plenitud del objeto, todo aspecto de la cosa, como parte implicada del sistema y por su capacidad de referirse a otros aspectos de la misma cosa, puede llegar a evocar la cosa, pues "cada apariencia de la cosa posee, de cierta forma, toda la cosa" (Levinas 2004, 33). 
La cosa percibida se presenta mediante toda percepción particular de una manera incompleta y limitada por vía de escorzo o matización unilateral. Al percibirse de hecho la cosa según un determinado aspecto, se presentará en cuanto perceptible según una pluralidad de aspectos (Gurwitsch 1979, 327).

Frente a la limitación ineludible, lo que queda es reunir perspectivas; como diría Husserl, obtener una pluralidad de nóemas perceptivos o de apariencias en escorzo para, de todas ellas, colegir aquellos elementos que, pese a nuestra variación, se mantienen intactos, esto es, los elementos estructurales que evidencien la esencia o eidos de la cosa atendida. Hablamos de algo semejante a lo que Ortega citaba como componer el torrente de lo real; de la percepción como la captación de la realidad dada a modo de apariciones, en un sistema noemático ${ }^{18}$ el cual, conformado por una secuencia noemática o composición de puntos de vista, como apuntara Husserl, se expande con cada nueva mirada, con cada nuevo nóema a modo de sistema siempre abierto e inagotable. A cada mirada, un nuevo aspecto se suma al sistema, lo que supone una reorganización del mismo, una revisión de la unidad establecida que permite y asegura que este último aspecto concuerde con la idea que de la cosa tenemos, es decir, que se comprehenda en su horizonte interno "en conformidad con ciertos lineamientos generales o típicos" (Gurwitsch 1979, 285), respetando las condiciones de coherencia, armonía o acuerdo necesarias para ser incluida en el sistema ${ }^{19}$. De algún modo, sucede que las vistas anticipatorias y las miradas ulteriores que al objeto lancemos se codeterminan unas a otras mediante referencia recíproca: mientras unas crean expectativas, las otras responden completando o actualizando el proceso perceptivo. Tal es el mecanismo, a grandes trazos, que conforma la idea que de la cosa material percibida obtengamos, mediante concatenación de nóemas.

Con todo, lo que advertimos es que, en tanto sistema, ninguno logrará actualizarse en su totalidad. Frente a la cosa percibida siempre hallaremos, en cada aspecto nuevo, referencias a otros aún no presentados, aspectos virtuales o latentes que anticipan o aluden a nuevos aspectos, a la espera de nuevas miradas para emerger. Por ello avisa Husserl que el objeto de percepción es, como hemos apuntado, un sistema siempre abierto e inagotable frente al cual, para obtener su totalidad, debiéramos conjuntar o yuxtaponer todas las miradas habidas y por haber, lo que resulta existencialmente impracticable. Solo un ser extramundano podría tener semejante don. En tanto humanos, estamos condenados a atender, esto es, a seleccionar. Ahora bien, como anticipamos, no nos exime dicha restricción de intentar reconstruir Babel.

La pluralidad de perspectivas se puede armonizar, como hemos visto, mediante continuas y reiteradas miradas al objeto, algo así como el trazado de un itinerario de miradas o

18 En cada vista o experiencia sensible, lo experimentado en cada caso se incluye en el seno de un horizonte -interno- conformado por el conjunto de experiencias sensibles y que incluye, a su vez, las referencias o anticipaciones que co-constituirán o co-determinarán el sistema que conforma la cosa vista, organizado a modo de estructura típica o genérica. Cfr. Husserl, E. (1980), Experiencia y juicio. Investigaciones acerca de la genealogía de la lógica. México: UNAM.

19 Gurwitsch, A. (1979): El campo de la conciencia. Un análisis fenomenológico. Madrid: Alianza Ed., pp. 245 y sig. 
series dialécticas ${ }^{20}$ por las que ir completando el conocimiento de la cosa vista. No obstante, aun con todo, seguiríamos muy limitados espacio-temporalmente en tanto individuos, pues "ningún hombre ha vivido íntegro el paisaje de la especie" (OC, III, 752-753). Frente a la limitación monádica solo cabe contar con el otro, tener en cuenta las miradas de ese "otro necesario" yuxtaponiendo "lo que cada uno de nosotros ve en el mundo a lo que ven, han visto y verán los demás individuos para obtener el escenario total de nuestra especie" (Ibid.).

En ello creía Ortega, como tantos contemporáneos suyos. En el primer tercio de siglo, quizá ya no tanto tras la Gran Guerra, pervivía cierta simpatía o consideración por la mirada del prójimo -bien a favor, bien en contra-; el otro se consideraba todavía prójimo (en sentido de proximidad), pues de algún modo se compartía proyecto o el proyecto se erigía con respecto al de los demás; sea el caso de quienes compartían el sueño europeo, o de los que colaboraban en el vínculo piadoso, algunos se abrazaban a la esperanza comunista quien no en los fascismos, en todo caso se construía la identidad de uno pegado a un ideal y teniendo en cuenta al otro presente; todos frente a un futuro que concedía espacios para la esperanza, pues "prometía" la estructura suficiente para desplegar los proyectos vitales de cada ciudadano en tanto individuos y en tanto comunidad. Habían, por tanto, intereses supeditados, compartidos o confrontados; la mirada al otro no solo era tenida en cuenta, resultaba necesaria. Por ello no era inusual ver enfatizada la idea de que, contando con el otro, nuestro conocimiento de la realidad podría ser mayor, óptimo, pues el otro realmente se sentía como parte necesaria para desplegar nuestro proyecto de vida. Cien años después, como se dice popularmente, ha llovido mucho.

En primer lugar las utopías, esos sueños por aproximarnos a sociedades más solidarias y justas que antaño nos movían, han dejado de tener su efecto proyectivo. Después de nuestro trémulo y desilusionante siglo XX han ido perdiendo credibilidad y su efecto motivador se ha disipado. Con ellas, los posibles futuros, ahora aparentemente inalcanzables, han quedado desatendidos al caer fuera de nuestro registro de intereses; nuestros proyectos de vida se han visto cercenados en su proyección temporal a causa de una terrible incertidumbre. El futuro, atendiendo al presente actual, no es un tiempo del que podamos esperar una sociedad solidaria y "salvadora" donde apoyarnos ${ }^{21}$. Como apunta Bauman $(2017,61)$, "el número de turistas que desean visitar y explorar ese extranjero país del futuro está cayendo en picado", no solo estamos cansados de esperar futuros posibles que nunca llegan, es que nuestro presente nos está dando buenas razones para temerlos; un presente donde, como hemos indicado, solo hallamos desigualdad, abandono institucional, corrupción, falta de empleo... en definitiva, un presente nada solidario, tan negligente que casi parece invitarnos, si seguimos pindáricamente comprometidos con nuestro proyecto vital, a la desconexión respecto de él -así como del otro en tanto parte-. Frente a ello, pues, frente a esta visión del presente y a semejante falta de expectativas respecto del futuro, el sujeto contemporáneo parece no hallar más subterfugio que en el único topos que le queda a la mano: su pasado. Harto de quimeras y de esperanzas rotas, rompemos con el presente e ignoramos el futuro para abrazar

20 “'Pararse', 'seguir', 'conservar' e 'integrar' son, pues, las cuatro acciones que el pensar dialéctico ejecuta [...] todo el quid está en cada 'vista' de un 'aspecto' reclama que avancemos para ver otro [...] tiene que recorrerlos todos" (OC, IX, 608). Epílogo de la filosofía, 1943.

21 Cfr. Drucker, P.F. (1990), Las Nuevas realidades: En el estado y la política. En la economía y en los negocios. En la sociedad y en imagen del mundo, Barcelona: Edhasa. 
un mundo ideal edificado sobre nuestros propios recuerdos reconstruidos, una nostalgia que poco a poco va tornándose el pathos dominante; una nostalgia que, por su radicación en los recuerdos, comporta un inevitable "retorno al yo" de significativas consecuencias en nuestro modo de ver el mundo, radicalizando el propio punto de vista y reduciendo esa esperanzadora hermenéutica de las vidas ajenas a una danza interesada de esporádicos encuentros. Ello, como veremos, no solo empobrece el número de nóemas por "cosa" conocida al desestimar la mirada del otro, lo empobrece aún más si cabe por la contradictoria idea de ver el mundo únicamente bajo el prisma de las miradas ya esbozadas, repetidas, restauradas.

\section{La nostalgia restauradora, el ocaso de la hermenéutica del punto de vista ajeno}

Es preciso apuntar, antes de abordar la nostalgia, que la mirada nostálgica ${ }^{22}$ per se en nada se contrapone a la visión que otro pueda tener del mundo en torno y a su reciprocidad con la propia, no es la nostalgia quien aísla al individuo sino la utilización que de ella se haga. La nostalgia únicamente es el efecto emocional que provoca la mirada hacia nuestros recuerdos -o hacia nuestra memoria colectiva- cuando buscamos en ellos el hogar desaparecido y que añoramos pues, según creemos y esperamos, en él podremos encontrar la postrera y única posibilidad de prosperar. Como apunta Bauman $(2017,14)$, la esperanza de vincularse emocionalmente a esos mundos perdidos, robados o abandonados que, a pesar de ello, se resisten a morir, perdura, pues en caso de poder recuperarlos nos ofrecerían el lugar deseado para desplegar nuestro proyecto de vida. Ahora bien, y en esto estamos con Svetlana Boym, el sentimiento nostálgico sufre una bifurcación en su expresión según sean nuestras intenciones cuando nos sumergirnos en el pasado; como apunta la autora ${ }^{23}$, existe una diferencia fundamental entre la nostalgia evocada por un afán restaurativo y la que proviene de un estilo reflexivo.

La nostalgia restaurativa es, según Boym, aquella que pretende hallar en el pasado lo que se entiende como una verdad absoluta que debemos reponer si pretendemos nuestra salvación. El nostálgico restaurativo pretende la reconstrucción de un pasado ideal e idealizado - por lo que no cabe decadencia alguna- procurando su diligente repetición, una repetición de identidad entre lo que fue y lo que debe ser. Es, pues, una pretensión imperativa, impositiva, que reivindica la estricta recreación del pasado estableciendo una pauta normativa de acción, lo que comporta, como veremos, importantes conflictos con la realidad presente (v. g. el fundamentalismo islámico, los nacionalismos acérrimos, etc.). La diferencia fundamental con la reflexiva recae justamente en ello, en que la reflexiva rehúye tales identidades; más bien utiliza el pasado y medita sobre él, elude reconstruir ese hogar mítico siendo muy consciente de la distancia entre identidad y semejanza. De algún modo, la nostalgia reflexiva acepta los vestigios por los que reconocemos el pasado en tanto lo que son, admitiendo la

22 Del griego nostos (regreso al hogar) y algia (dolor, añoranza), es un sentimiento de pérdida y desplazamiento. Aunque de raíz griega, es un concepto de acuñación relativamente reciente, por Johannes Hofer en 1688, para dar nombre a una enfermedad muy extendida entre los estudiantes, criados o soldados suizos que, lejos de su patria, sentían añoranza de su tierra natal. Boym $(2015,34)$ la define, "en cuanto a emoción histórica, es la añoranza de ese 'espacio de experiencia' menguante que ya no encaja en el nuevo horizonte de expectativas [...] efectos secundarios de la teleología del progreso".

23 Boym, S. (2015), El futuro de la nostalgia, Madrid: Antonio Machado libros. 
ya no existencia de ese pasado aunque aproveche su inspiración para actuar en el presente ${ }^{24}$. Esta modalidad, menos idealista, más fenoménica, por estar bien localizada no aspira más que a lo pasado en el presente, un pasado que, mediante sus huellas, nos vincula con el hecho social -con la tradición- por lo que afianza la sensación de pertenencia y posibilita el diálogo. A diferencia de la mirada restauradora, nada tiene que ver con la imposición de un orden que se cree que fue y se exige que vuelva a ser; la reflexiva es una nostalgia de la que nos atrevemos a ironizar, a reflexionar, a aprender y que, bien gestionada, puede incluso servir para curar heridas sociales (sentimientos de desarraigo, traumas sociales) ${ }^{25}$, pues desde la consciencia de fragmentariedad e inconclusión que alberga ${ }^{26}$-en tanto somos conscientes que de ella únicamente tenemos aspectos en forma de recuerdos o vestigios que nos ceden un relato inconcluso e interpretable-, nos devuelve a la mirada sistémica, a la que desconcha en cada gesto nóemas siempre nuevos de lo mirado en un proceso abierto $e$ inagotable; esa mirada que, por su carácter, permite la intervención del otro reclamando la anhelada hermenéutica del punto de vista ajeno, reivindicando el ansiado diálogo frente a los efectos, estos sí, devastadores de la nostalgia restaurativa.

Esta, la restaurativa, por su idealizada pretensión de repetir e imponer el canon pretérito, tiene consecuencias bien distintas en su expresión. Aparentemente se presenta como la oportunidad de volver a vivir el pasado, como un camino de restauración por el que reponer los errores cometidos y allanar el camino a nuevas oportunidades. De algún modo esperamos hallar, en ese terreno imaginario sustentado en recuerdos, los medios y las oportunidades que el presente y el futuro posible nos niegan. Ahora bien, más allá de las sugerentes promesas, dicho camino se encuentra solo en nuestros recuerdos o en lo que en nosotros hay del imaginario colectivo, no hay nada más allá. En rigor, el nostálgico es un camino que se anda hacia adentro, hacia el no-lugar de nuestra mente, donde se almacenan las imágenes del pasado, hacia el hogar que ya no existe; puede que incluso las imágenes que guardamos disten mucho de lo que en su momento realmente fue ese pasado, si es que en algún momento lo fue, pues no en pocas ocasiones añoramos promesas no cumplidas que esperamos realizar ${ }^{27}$. La nostalgia tiende a confundir el hogar real con el imaginario siendo, en extremo, no más que un idilio con la fantasía individual ${ }^{28}$ que se compromete con algo que ya no es. Por ello, cuando rige el comportamiento presente y lo hace de un modo imperativo, cuando el sujeto abrumado por la nostalgia intenta restaurar los condicionantes que ese pasado requiere para hallar su posibilidad de realización, las perturbaciones en el modo de vincularse cognoscitivamente con la realidad están servidas, y las consecuencias sociales de dicha relación las conocemos a diario en los noticiarios.

24 Cfr. Ibid., pp. 83 y sig.

25 Algunos estudios avalan los efectos beneficiosos de trabajar la nostalgia como remedio para curar heridas como las producidas por los cambios drásticos en los espacios urbanos (Adams D. y P. Larkham, (2016), "Walking with the ghosts of the past: Unearthing the value of residents' urban nostalgias", Urban Studies, 53/10, pp. 2004-2022), o las sufridas por desplazamientos o migraciones forzadas para exorcizar fantasmas de un tiempo y un espacio perdido (Cuya Gavilano, L. (2016), "Internal Migration, the Publishing Industry, and Transnational Identities in Two Peruvian Writers", Revista hispánica moderna, 69/1, pp. 1-16).

26 Boym, S. op., cit..

27 Ver Paniagua, C. (2010), "Psicología de la nostalgia”. Dendra Médica. Revista de Humanidades, 9/1, pp. 39-48.

28 Boym, S. op. cit., pp. 14 y16. 
Como idilio con la fantasía, la búsqueda del pasado parte fundamentalmente de un encierro para con uno mismo, pues la fantasía es radicalmente particular. Ello implica, por efecto, un distanciamiento respecto de los demás, de ese prójimo que ya no se abre al mundo como lo hago yo, que no lo ve tal y como yo lo deseo ver; es más, de un prójimo que, al igual que yo, va enclaustrándose tras su nostálgica mirada alimentando la falta de simpatía entre nosotros. No es difícil observar, hoy en día, un generalizado movimiento autorreferencial que, a parte y en consecuencia de nuestro giro centrípeto, nos conduce no solamente al aislamiento sino que, por ello y en ello, a entender el punto de vista ajeno como algo instrumental, casi deshumanizado, de lo que aprovecharse o, en su defecto, protegerse ${ }^{29}$. "Las personas no se escuchan unas a otras, porque, en realidad, no se oyen unas a otras. La información que respalda sus creencias tiene una significación emocional para ellas y es la que se procesa. Todo lo demás se desecha" (Rozenblit 2008, pp. 74-75) ${ }^{30}$, es excluido como parte ajena u hostil a mi modo de ver el mundo. En términos perspectivistas diríamos que, desde nuestra tendencia al pasado, la cosa percibida, esa que se complementa necesariamente con las miradas futuras y confiando en la mirada ajena, solo será aceptada en su estricta visión individual, vista por mí; es más, lo será, dado mi afán retrospectivo, a través de las miradas ya vistas, repetidas o vueltas a mirar, lo que acaba restringiendo enormemente mi visión de la cosa, sin decir que, estrictamente, es imposible, pues no se puede volver a ver lo ya visto idénticamente, dado que toda revisión de lo ya visto es una nueva mirada, una reinterpretación o acto creativo; dicho de otro modo, no podemos más que reinterpretar lo ya visto a través del recuerdo de lo vivido y del presente siempre cambiante en que nos encontremos, lo que nos encierra en una espiral viciosa de aires románticos con una, cada vez, más pobre comprensión de la cosa percibida.

Pero los efectos de la mirada nostálgica no acaban, como decimos, en el estrechamiento perspectivo, a él se le suma la creciente desconfianza en el punto de vista ajeno, cada vez más desemejante al mío y que produce, en todo caso, un distanciamiento respecto de la mayoría, o un acotamiento social que se respalda sobre el restringido elenco de "nosotros" que pueda rescatar efímeramente para mi beneficio. Ello deja a los "otros" como más "otros" que nunca, quedando, en consecuencia, más solos que nunca ${ }^{31}$. Esta tendencia tiende a traducirse en una exaltación de lo "local", inicialmente de lo radicalmente local -lo individual-, que, por la necesidad de reconstruir ese mundo recordado, nos lleva a la vinculación paranoide con aquellos que parecen compartir nuestra visión. Como decimos, bajo el prisma nostálgico, las alianzas se tornan más interesadas que nunca; las simpatías o la idea de "nosotros" se vuelve esporádica, pasajera, y varía según el contexto y los intereses compar$\operatorname{tidos}^{32}$. En un determinado momento mis intereses me aproximarán a un determinado grupo social, lo que no excluye que en otro lo abandone por un grupo distinto o combine ambos según me convenga, no con la intención de compartir puntos de vista, sino únicamente de ratificar el mío. El grupo, el otro, se instrumentaliza para satisfacer intereses particulares independientemente de los vínculos personales. Ello engendra todo tipo de desconfianzas

29 El actual sistema de mercado laboral, por ejemplo, tiende a cosificar a los sujetos tornándolos mercancía y consolidando un modelo de competencia y rivalidad que alimenta la desconfianza entre ellos.

30 Traducción propia del original en inglés.

31 Bauman apostilla a este efecto como un regreso a las tribus. (Bauman, Z. op., cit.).

32 Ver: Bauman, Z. (2003), La Modernidad líquida, México: FEC. 
y hostilidades, incluso violencias de las que, desafortunadamente, como indicamos, tenemos noticias a diario a causa de los conocidos rebrotes nacionalistas, de la consolidación y expresión de los integrismos fundamentalistas, de las políticas basadas en el miedo o de sus reacciones electorales.

Frente a semejante panorama, pues, el intento de reconstruir Babel, de yuxtaponer el conjunto de miradas ajenas que describíamos al comienzo de este artículo, queda terriblemente maltrecho. La mirada nostálgica, en su acepción restaurativa, es una amenaza sería a la cohabitación en tanto se nos formula como un ocaso para la interpretación de vidas ajenas, de esas miradas complementarias que ya no sirven, que no interesan salvo que ratifiquen o revaliden mi propio y actual punto de vista; en cualquier otro caso, son consideradas como potenciales agresoras de las que parece mejor alejarse, a las que es mejor desatender.

\section{En conclusión}

Siendo que la nostalgia, entendida bajo un prisma restaurativo, se halla en tantas expresiones sociales, algunas de ellas violentas, o encubriendo actitudes de odio frente a quien no comparte el proyecto vital del restaurador, entendemos que es algo frente a lo que no podemos ponernos de perfil. Como filósofos, en tanto estudiosos de la vida y amantes de lo humano, tenemos el compromiso de describir la cuestión y esbozar posibilidades de enmienda a sus efectos. Ahora bien, pocos antídotos caben frente a algo que nos subyace tan profundamente como la nostalgia.

En tanto idilio con el pasado, convendría pensar como un primer remedio el contraponer al nostálgico un futuro esperanzador, pero este es un tiempo tan ilusorio como el mismo pasado. Lanzar promesas al viento que contrarresten los ofrecimientos del pasado es un remedio del que ya estamos habituados y no ejerce efecto alguno, es más, volver al tiempo de las utopías, paradójicamente, tendría mucho de nostálgico. Por tanto, el futuro se esfuma por su misma volatilidad de la ecuación. No descubrimos nada nuevo cuando afirmamos, pues, que solo nos queda el presente para neutralizar los anhelos pretéritos. Cualquier posibilidad de romper con esta tendencia idealista solo tiene cabida si parte de un cambio efectivo en el momento actual; cualquier posibilidad de cambio que permita a nuestra mirada, a nuestra atención, anidar en nuevos horizontes deberá irrumpir de la asunción de lo que ahora somos, pues solo sabiendo quienes somos y a qué aspiran nuestros anhelos albergaremos el necesario conocimiento sobre qué precisamos para poder serlo plenamente: y lo que somos, como venimos predicando, es ni más ni menos que sujetos nostálgicos.

La nostalgia, pese a los riesgos a que nos expone en tanto comunidad, es parte de nuestro pathos particular; como una niebla se extiende, en mayor o menor medida, a lo largo y ancho de toda la sociedad occidental -al menos en ella, seguramente mucho más allá- bosquejando la sensibilidad de nuestro tiempo, el modo de mirar, de atender y entender la realidad en torno, hasta lo estético se viste de nostalgia (modas vintage, remakes cinematográficos, sagas o series televisivas redimidas y extendidas para el público nostálgico), pues eso demandan nuestros intereses. Ahora bien, asumirla como parte de lo que somos no significa que debamos sucumbir a su uso utópico o restaurativo, al impulso visceral y revolucionario de restaurar un orden perdido o nunca dado. 
Más que nunca precisamos mantener los pies sobre la tierra y, como diría Husserl, volver a las cosas mismas; aceptar la nostalgia en tanto lo que es, un efecto emocional que provoca la mirada hacia nuestros recuerdos, nada más y nada menos; una emoción localizada, presente, quizá balsámica pero, como los recuerdos en los que se basa, enraizada en el presente, pues no existe recuerdo o emoción posible, como no existe mirada posible, que no sea, precisamente, localizada:

es el caso que la realidad, como un paisaje, tiene infinitas perspectivas, todas ellas igualmente verídicas y auténticas. La sola perspectiva es esa que pretende ser la única. Dicho de otra manera; lo falso es la utopía, la verdad no localizada, vista desde 'lugar ninguno'. El utopista [...] es el que más yerra, porque es el hombre que no se conserva fiel a su punto de vista, que deserta de su puesto (OC, III, 614).

Bien podría valer esta condena también para el nostálgico restaurativo. La perspectiva auténtica es aquella que se sabe particular, así lo entendemos tras un análisis fenomenológico de la misma, pero también la que se sabe parte de un sistema infinito e inabarcable, pues en tanto es la única que radica en su puesto, en su situación mundana, sabe de sus limitaciones, vive con y de ellas. Quien idealiza su mirada, quien la convierte en utópica y la cree única y suficiente, pierde la coordenada que le sitúa, pervierte su punto de vista, como le sucede al nostálgico restaurativo.

Afortunadamente, cabe otra forma de entender la nostalgia una vez asumida como parte de lo que somos: reflexivamente. La nostalgia reflexiva, como decíamos, justamente por estar bien localizada, no aspira más que a lo pasado en el presente y, por ello, nos vincula con la tradición en tanto lo que es, un recuerdo - personal y/o colectivo- que se nos da como algo que ya no es pero que, no por ello, deja de ser fuente de inspiración a nuestras acciones presentes y proyectos venideros. La reflexiva, como se está demostrando ${ }^{33}$, quizá sea la forma más efectiva de curar heridas y de recuperar la fe en el otro; la vía para vincularnos con la memoria colectiva, con todos los otros; quizá el único camino que nos queda a los nostálgicos de recuperar nuestro presente y, con él, reencontrarnos con un proyecto de futuro, pero estos son ya otros asuntos.

\section{Referencias}

Adams David y Peter Larkham (2016): "Walking with the ghosts of the past: Unearthing the value of residents' urban nostalgias”, Urban Studies, 53/10, pp. 2004-2022.

Bauman, Zigmund (2017): Retrotopía, Barcelona: Paidós.

Bauman, Zigmund (2003): La Modernidad líquida, México: FEC.

Boym, Svetlana (2015): El futuro de la nostalgia, Madrid: Antonio Machado libros.

Cuya Gavilano, Lorena (2016), "Internal Migration, the Publishing Industry, and Transnational Identities in Two Peruvian Writers", Revista hispánica moderna, 69/1, pp. 1-16.

Drucker, Peter F. (1990): Las Nuevas realidades: En el estado y la política. En la economía y en los negocios. En la sociedad y en imagen del mundo, Barcelona: Edhasa.

33 Ver nota 23. 
Gurwitsch, Aron (1979): El campo de la conciencia. Un análisis fenomenológico. Madrid: Alianza.

Husserl, Edmund (1980): Experiencia y juicio. Investigaciones acerca de la genealogía de la lógica. México: UNAM.

Husserl, Edmund (2013): Ideas relativas a una fenomenología pura y una filosofía fenomenológica, México: UNAM.

Husserl, Edmund (2014): Investigaciones lógicas, 2. Madrid: Alianza.

Lakoff, George (2007): No pienses en un elefante: lenguaje y debate político, Madrid: Complutense.

Levinas, Emmanuel (2004): La teoría fenomenológica de la intuición. Salamanca: Sígueme. Lowenthal, David (1997): The heritage crusade and the spoils of history, Londres: Viking. Morón Arroyo, Ciriaco (1968): El sistema de Ortega y Gasset, Madrid: Alcalá.

Ortega y Gasset, José (2004a): Meditaciones del Quijote, Obras Completas, I. Madrid: Taurus.

Ortega y Gasset, José (2004b): Verdad y perspectiva, Obras Completas, II. Madrid: Taurus. Ortega y Gasset, José (2004c): Dios a la vista, Obras Completas, II. Madrid: Taurus.

Ortega y Gasset, José (2005a): El tema de nuestro tiempo. Obras Completas, III. Madrid: Taurus.

Ortega y Gasset, José (2005b): Las Atlántidas. Obras Completas, III. Madrid: Taurus.

Ortega y Gasset, José (2005c): La deshumanización del arte e ideas sobre la novela. Obras Completas, III. Madrid: Taurus.

Ortega y Gasset, José (2005d): Estudios sobre el corazón. Obras Completas, IV. Madrid: Taurus.

Ortega y Gasset, José (2008): ¿Qué es filosofía? Obras Completas, VIII. Madrid: Taurus.

Ortega y Gasset, José (2009): Epílogo de la filosofía. Obras Completas, IX. Madrid: Taurus. Paniagua, C. (2010): "Psicología de la nostalgia". Dendra Médica. Revista de Humanidades, 9/1, pp. 39-48.

Rodríguez Huéscar, Antonio (1985): Perspectiva y verdad, Madrid: Alianza.

Roselló, Jaume, Munar, Enric, Obrador, P., Cardell, E., (2007): "Historia conceptual de la atención”. Revista de historia de la Psicología, vol. 28, núm. 2/3, pp. 59-65.

Rozenblit, Bruce (2008): Us against them: How tribalism affects the way we think, Transcendent publications.

San Martín, Javier (2008): "La percepción como interpretación”. Investigaciones fenomenológicas, 6, pp. 13-32.

Schapp, Wilhelm (1919): Beiträge zur Phänomenologie der Wahrnehmung, Gotinga: M. Niemeyer, Halle/S

Scheler, M. F. (2001): Ética: nuevo ensayo de fundamentación de un personalismo ético, Madrid: Caparrós. 